\title{
Albright's hereditary osteodystrophy
}

\author{
Zaw Min $\cdot$ Sunita Sharma $\cdot$ Luis Rivera-Ramirez
}

Received: 4 September 2013/Accepted: 7 October 2013/Published online: 18 October 2013

(C) SIMI 2013

A 22-year-old man was referred to our endocrine clinic for evaluation of asymptomatic hypocalcemia. His past medical history included hypothyroidism on oral thyroxine replacement. On physical examination, he was obese and had a short stature with a round face. Both of his fourth and fifth fingers were shortened (Fig. 1a) with absence of the fourth and fifth knuckles on clenched fists, showing the characteristic "knuckle, knuckle, dimple, dimple" appearance (Fig. 1b). The patient reported that his mother also had shortened ring fingers (Fig. 1c) and dimpling over the fourth knuckles of clenched fists (Fig. 1d). Significant laboratory investigations showed a low calcium level of $7.8 \mathrm{mg} / \mathrm{dL}$ (normal $8.4-10.2 \mathrm{mg} / \mathrm{dL}$ ), a high phosphate level of $5 \mathrm{mg} / \mathrm{dL}$ (normal $2.5-4.5 \mathrm{mg} / \mathrm{dL}$ ), and markedly elevated parathyroid hormone (PTH) level of $496 \mathrm{pg} / \mathrm{dL}$ (normal 12-65 pg/dL). His 25-hydroxy vitamin D level was within normal range. In contrast, his mother had normal calcium, phosphate, vitamin D and PTH levels. The patient's clinical features, including short stature, obesity, round face, and shortening of the fourth and fifth metacarpal bones, are compatible with those of Albright's

\section{Z. Min $(\bowtie)$}

Department of Medicine, Division of Infectious Diseases, Allegheny General Hospital, 420 East North Avenue, East Wing, Suite 407, Pittsburgh, PA 15212, USA

e-mail: zmin@wpahs.org

\section{S. Sharma}

Department of Medicine, MedStar Franklin Square Medical Center, 9000 Franklin Square Drive, Baltimore, MD 21237, USA

e-mail: mailsunitasharma@googlemail.com

\section{Rivera-Ramirez}

Diabetes and Endocrinology Center, MedStar Harbor Hospital, 3001 South Hanover Street, Baltimore, MD 21225, USA

e-mail: luis.rivera-ramirez@medstar.net hereditary osteodystrophy (AHO). Given his family history, hypothyroidism, biochemical abnormalities, and characteristic physical findings of AHO, the patient was diagnosed as pseudohypoparathyroidism type Ia (PHP-Ia). The patient's mother, on the other hand, was diagnosed as pseudo-pseudohypoparathyroidism (PPHP) due to lack of disturbances of calcium homeostasis. The patient was treated with oral vitamin D and calcium supplements. After 3 months of therapy, his serum calcium, phosphate and PTH levels were normalized.

One of the skeletal abnormalities of AHO_- "knuckle, knuckle, dimple, dimple" appearance of the hand resulting from premature closure of the epiphyses-is known as knuckle-dimple sign or Archibald's sign (Fig. 1b, d) [1, 2]. Clinical manifestations of $\mathrm{AHO}$ can be present in both PHP-Ia and PPHP. There are different forms of PHP, namely, type I (subdivided into type Ia and Ib) and type II. Their working classifications, biochemical and clinical findings are described as in Table 1 [3]. The PHP-I is the most common and is due to mutations in the GNAS gene. This gene codes for the stimulatory alpha-subunit of the trimeric Gs protein that connects G-protein coupled receptors of various hormones (particularly thyroid-stimulating hormone, TSH) with their intracellular signaling cascades $[3,4]$. The primary response to PTH by the kidneys is to increase renal tubular calcium reabsorption and phosphate excretion. Mutations in GNAS gene lead to hormonal resistance of renal tissues to PTH, which causes hypocalcemia and hyperphosphatemia; and a decreased response to TSH results in primary hypothyroidism.

The patient's mother has a phenotype of AHO with preserved calcium metabolism, consistent with PPHP (Table 1). PPHP characteristically displays an inheritance pattern known as tissue-specific paternal gene imprintingonly females can transmit the full disease with 

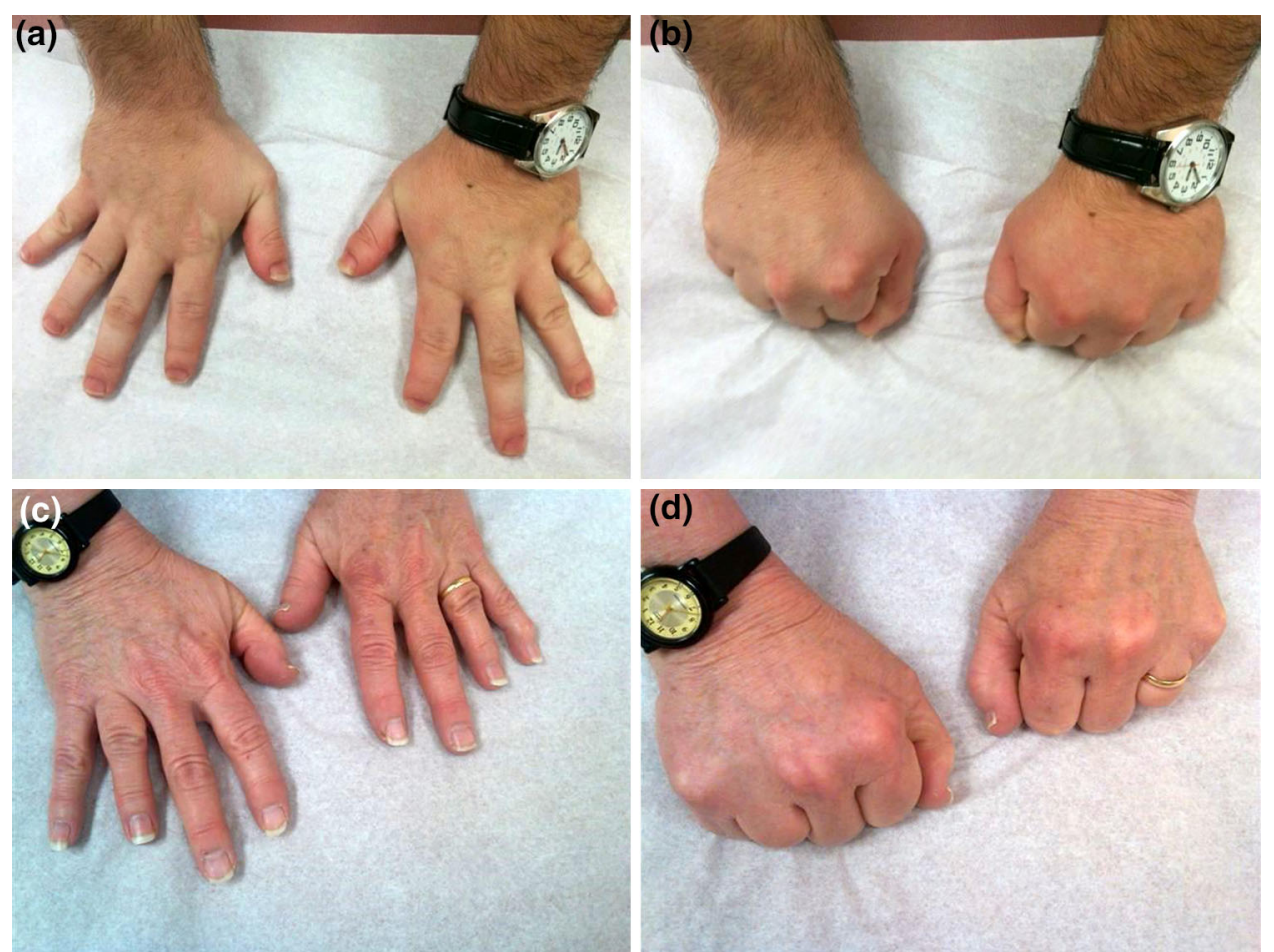

Fig. 1 Patient's hands: a shortened fourth and fifth fingers, b Archibald's sign-absence of the fourth and fifth knuckles ("knuckle, knuckle, dimple, dimple") on clenched fists. Patient's mother's hands: c shortened ring fingers, d Archibald's sign-absence of the fourth knuckle on clenched fists

Table 1 Biochemical findings and physical manifestations in pseudohypoparathyroidism (PHP) and pseudo-pseudohypoparathyroidism (PPHP) [3]

\begin{tabular}{clll}
\hline Type & $\begin{array}{l}\text { Hypocalcemia, } \\
\text { hyperphosphatemia }\end{array}$ & $\begin{array}{l}\text { Serum } \\
\text { parathyroid } \\
\text { hormone (PTH) }\end{array}$ & $\begin{array}{l}\text { Albright's } \\
\text { hereditary } \\
\text { osteodystrophy } \\
\text { (AHO) }\end{array}$ \\
\hline $\begin{array}{c}\text { PHP- } \\
\text { Ia }\end{array}$ & + & Increased & + \\
$\begin{array}{c}\text { PHP- } \\
\text { Ib }\end{array}$ & Increased & - \\
PHP- \\
II \\
PPHP -
\end{tabular}

+ , presence; - , absence

hypocalcemia [4]. The paternal defective allele of GNAS gene is imprinted (silenced) in the renal cortex (where the disease manifestation is expressed), so that the disease PHP-Ia can never be inherited from the father carrying the defective allele but only from a mother whose allelic product is critical for the PTH-dependent function in the kidney [3-5]. Therefore, it appears that our patient inherited a mutated allele of GNAS gene from his mother [5]. It creates a different phenotype in which the patient has the same skeletal defects of AHO but there are hypocalcemia, hyperphosphatemia, and high serum PTH level secondary to renal PTH resistance, indicative of PHP-Ia. Our case highlights patients with PPHP can co-exist with PHP-Ia in the same family but never in the same generation [3-5]. The treatment modalities of PHP-Ia are calcium and vitamin D replacements to restore normal calcium level [3].

In summary, the presence of a constellation of physical manifestations of AHO, particularly Archibald's sign, helps practicing physicians recognize a rare genetic endocrine disorder within the family members and reach the correct diagnosis.

Conflict of interest None.

\section{References}

1. Nagarajan V, Sharma P (2013) Knuckle-dimple sign. QJM 106(1):83-84

2. Goswami M, Verma M, Singh A, Grewal H, Kumar G (2009) Albright hereditary osteodystrophy: a rare case report. J Indian Soc Pedod Prev Dent 27:184-188

3. Potts JT, Jüppner H (2012) Disorders of the parathyroid gland and calcium homeostasis. In: Longo DL, Fauci AS, Kasper DL, Hauser SL, Jameson JL, Loscalzo J (eds) Chapter 353. Harrison's principles of internal medicine, 18th edn. McGraw-Hill, New York

4. Davies SJ, Hughes HE (1993) Imprinting in Albright's hereditary osteodystrophy. J Med Genet 30(2):101-103

5. Mann JB, Alterman S, Hills AG (1962) Albright's hereditary osteodystrophy comprising pseudohypoparathyroidism and pseudo-pseudohypoparathyroidism with a report of two cases representing the complete syndrome occurring in successive generations. Ann Intern Med 56:315-342 